\title{
INFLUENCIA DE CONDIÇÕES OPERACIONAIS DA SECAGEM DE CAPIM-CIDREIRA (CYMBOPOGON CITRATUS (DC.) STAPF.) SOBRE O RENDIMENTO DO PROCESSO DE OBTENÇÃO DO ÓLEO ESSENCIAL
}

\author{
G. C. BONILHA ${ }^{1}$ e G. N. A. VIEIRA ${ }^{1}$ \\ ${ }^{1}$ Universidade Estadual Paulista "Júlio de Mesquita Filho”, Instituto de Química de \\ Araraquara, Departamento de Bioquímica e Tecnologia Química \\ E-mail para contato: gustavo.vieira@iq.unesp.br
}

\begin{abstract}
RESUMO - O processo de secagem de plantas medicinais como etapa precedente à obtenção do óleo essencial auxilia na conservação da matéria-prima, assim como, evita que a produção do óleo seja comprometida por fatores como a sazonalidade da planta. No entanto, a secagem pode influenciar sobre as características do óleo essencial. Neste trabalho, analisou-se a influência da temperatura, do tempo de secagem de folhas de capim-cidreira (Cymbopogon citratus (DC.) Stapf) e do tempo de hidrodestilação, sobre o rendimento do processo. Com base em um planejamento fatorial completo e uma análise de variância, verificou-se que somente as variáveis relacionadas à secagem influenciaram sobre o rendimento, o que pode ser explicado pela remoção de componentes do óleo essencial durante a secagem.
\end{abstract}

\section{INTRODUÇÃO}

Os óleos essenciais são substâncias presentes em algumas plantas, sendo, em muitos casos, as principais responsáveis pelo seu aroma e sabor. São compostos por uma mistura de componentes voláteis de diferentes funções químicas (Martim et al., 2012). Alguns desses componentes conferem características aromáticas de grande interesse na indústria alimentícia e na produção de artigos de higiene e limpeza. Existem também óleos essenciais que possuem propriedades terapêuticas importantes. Especificamente, as folhas do capim-cidreira (Cymbopogon citratus (D.C.) Stapf), também conhecido por capim-limão ou capim-santo, apresentam propriedades medicinais analgésicas, anti-inflamatórias e são também empregadas no tratamento de distúrbios gastrointestinais (Balti et al, 2014). O óleo essencial de capimcidreira é inibidor do desenvolvimento das larvas de alguns insetos transmissores de doenças, como o Aedes aegypti, além de possuir efeito repelente (Negrelle; Gomes, 2005). Devido ao seu alto teor de citral (Barbosa et al., 2008), o óleo essencial de capim-cidreira é aplicado nas indústrias alimentícias e de cosméticos, já que essa substância remete a aromas cítricos.

Os óleos essenciais podem ser obtidos através de processos como a hidrodestilação e o arraste a vapor. Na hidrodestilação, as plantas de interesse são imersas em água e o sistema é aquecido até que haja um destilado bifásico, composto pelo óleo essencial e por uma fase aquosa (hidrolato). Estas fases podem ser facilmente separadas por decantação simples (Kubeczka, 2010). Já no processo por arraste a vapor, o vapor de água - e não água líquida - 
estabelece contato com as plantas, havendo a vaporização do óleo essencial até o sistema de destilação e a consequente separação do hidrolato e do óleo essencial.

Podem-se obter óleos essenciais também após um processo de secagem do material. A secagem proporciona uma redução de perdas por contaminação biológica e por degradação causada pela atividade enzimática (Garcia; Ferreira, 2011). Desta forma, plantas das quais possam se obter óleos essenciais podem ser estocadas e podem estar disponíveis no mercado durante períodos mais longos, reduzindo a sazonalidade de certos óleos essenciais.

Apesar destes benefícios da secagem antes do processo de obtenção do óleo essencial, pode haver interferência da secagem sobre aspectos da qualidade do óleo e no rendimento do processo de obtenção do óleo essencial, em relação ao obtido da planta in natura (Arabhosseini et al., 2006). Em geral, observa-se que a secagem promove um aumento da concentração do componente principal do óleo essencial, mas, simultaneamente, restringe a variedade de compostos nele presentes (Buchaillot et al., 2009; Carvalho Filho et al., 2006; Figiel et al., 2010; Mejri et al., 2010). Foi constatado que altas temperaturas podem provocar degradação química de alguns componentes do óleo essencial. Já as temperaturas mais baixas favorecem a variedade de compostos, mas exigem uma maior duração de secagem, que, por sua vez, favorece a volatilização e oxidação de alguns componentes (Figiel et al., 2010).

Contudo, não são apenas as condições operacionais da secagem que influenciam na alteração da composição do óleo. Para processos envolvendo materiais biológicos diferentes na extração do óleo, são esperados resultados diferentes, justificando estudos individuais de cada espécie. Dada a importância do óleo essencial extraído das folhas do capim-cidreira, foi realizado um estudo das influências de condições operacionais da secagem e da hidrodestilação no rendimento do óleo essencial, de forma a otimizar o processo composto por essas duas etapas. Neste contexto, o trabalho visou à determinação das influências de algumas das variáveis dos processos (a temperatura de secagem, o tempo de secagem e o tempo de hidrodestilação) no rendimento em óleo essencial de capim-cidreira.

\section{MATERIAL E MÉTODOS}

Utilizaram-se folhas de plantas da espécie Cymbopogon citratus (D.C.) Stapf como material para os experimentos. As folhas foram colhidas no Instituto de Química de Araraquara, no intervalo entre $8 \mathrm{~h}$ e $10 \mathrm{~h}$ da manhã, durante o período de verão. É desejável padronizar um determinado horário do dia e período do ano para as colheitas, já que essas variáveis influenciam na composição química do produto extraído (Martim et al., 2012).

As folhas foram cortadas em retângulos de aproximadamente $5 \mathrm{~cm}$, distribuídas em placas de Petri, de massas previamente medidas, e submetidas à secagem em estufa de convecção natural, sob temperaturas de $40^{\circ} \mathrm{C}, 55^{\circ} \mathrm{C}$ ou $70^{\circ} \mathrm{C}$, dependendo do experimento. Foram estabelecidos tempos de secagem de $3 \mathrm{~h}, 4 \mathrm{~h}$ ou $5 \mathrm{~h}$, monitorados com um cronômetro. Posteriormente, mediram-se as massas das placas de Petri contendo as folhas secas em uma balança analítica. As folhas secas foram então transferidas para um balão de fundo redondo de $250 \mathrm{~mL}$, para proceder à obtenção do óleo essencial por hidrodestilação. Foram adicionados $150 \mathrm{~mL}$ de água destilada a este balão e este foi acoplado a um sistema para obtenção do óleo essencial. Um esquema do equipamento é mostrado na Figura 1. 
Figura 1 - Diagrama esquemático do sistema utilizado para obtenção do óleo essencial.

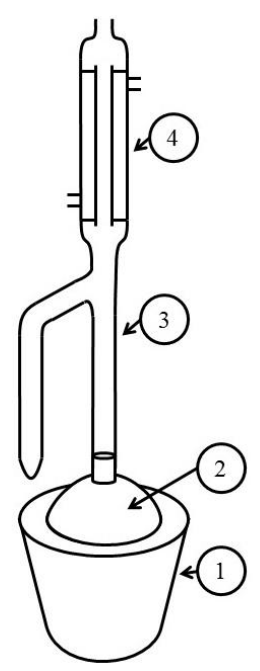
1) Manta de aquecimento
2) Balão de fundo redondo
3) Sistema tipo trap
4) Condensador

Foram realizados experimentos de hidrodestilação com duração de 0,5 h, 1,25 h, e 2 h, estabelecendo a contagem do tempo a partir do início da ebulição da água. Conforme o óleo essencial foi obtido no interior do trap, ele foi retirado com o auxílio de uma pipeta de Pasteur e transferido para um frasco de vidro âmbar. $\mathrm{O}$ frasco de cor âmbar foi adotado para diminuir a deterioração de componentes do óleo essencial causada pela luz. Após obtido todo o óleo durante o tempo de hidrodestilação estabelecido em cada experimento, mediu-se a massa de óleo coletada no intervalo. A partir destes dados, calculou-se o rendimento total do processo de hidrodestilação, baseado na razão entre a massa de óleo obtida e a massa de folhas secas.

Foi analisada a influência das variáveis temperatura de secagem (denotada por $T$ ), tempo de secagem $\left(t_{s}\right)$ e tempo de hidrodestilação $\left(t_{h}\right)$ sobre o rendimento do processo de hidrodestilação $(\eta)$. Os níveis das variáveis independentes foram escolhidos de modo a se obter um planejamento fatorial completo, com três réplicas no ponto central; totalizando, pois, 11 experimentos. Os dados experimentais foram analisados no software Statistica, realizandose uma análise de variância a um intervalo de confiança de $95 \%$.

\section{RESULTADOS E DISCUSSÃO}

A Tabela 1 apresenta os resultados de rendimentos de óleo essencial obtidos em função das condições operacionais adotadas para cada experimento.

Todos os rendimentos foram inferiores a $2 \%$. Resultados desta ordem de grandeza são comumente encontrados na literatura para a obtenção de óleos essenciais de diversas plantas, por diversos processos, inclusive do capim-cidreira (Balti et al., 2014; Barbosa et al., 2008; Martim et al., 2012). Em linhas gerais, rendimentos menores foram obtidos para tempos de secagem maiores. Tal resultado era esperado, considerando que tempos de secagem maiores podem fazer com que mais componentes do óleo essencial sejam volatilizados durante a secagem (Figiel et al., 2010). 


\section{C $\$$ BEQ T200

Tabela 1 - Condições operacionais de cada experimento e respectivos rendimentos.

\begin{tabular}{|c|c|c|c|c|c|c|c|c|}
\hline \multirow{2}{*}{ Exp. } & \multicolumn{2}{|c|}{$T$} & \multicolumn{2}{c|}{$\boldsymbol{t}_{\boldsymbol{s}}$} & \multicolumn{2}{c|}{$\boldsymbol{t}_{\boldsymbol{h}}$} & $\begin{array}{c}\text { Razão } \\
\text { sólido/água } \\
(\mathrm{g} / \mathrm{mL})\end{array}$ & $\begin{array}{c}\boldsymbol{\eta} \\
(\%)\end{array}$ \\
\cline { 2 - 7 } & $\begin{array}{c}\text { Variável } \\
\text { codificada }\end{array}$ & $\begin{array}{c}\text { Valor real } \\
\left({ }^{\circ} \mathrm{C}\right)\end{array}$ & $\begin{array}{c}\text { Variável } \\
\text { codificada }\end{array}$ & $\begin{array}{c}\text { Valor } \\
\text { real (h) }\end{array}$ & $\begin{array}{c}\text { Variável } \\
\text { codificada }\end{array}$ & $\begin{array}{c}\text { Valor } \\
\text { real (h) }\end{array}$ & & \\
\hline $\mathbf{1}$ & -1 & 40 & -1 & 3 & -1 & 0,5 & 0,467 & 1,44 \\
\hline $\mathbf{2}$ & 1 & 70 & -1 & 3 & -1 & 0,5 & 0,432 & 0,55 \\
\hline $\mathbf{3}$ & -1 & 40 & 1 & 5 & -1 & 0,5 & 0,322 & 0,44 \\
\hline $\mathbf{4}$ & 1 & 70 & 1 & 5 & -1 & 0,5 & 0,267 & 0,69 \\
\hline $\mathbf{5}$ & -1 & 40 & -1 & 3 & 1 & 2 & 0,467 & 0,53 \\
\hline $\mathbf{6}$ & 1 & 70 & -1 & 3 & 1 & 2 & 0,376 & 0,57 \\
\hline $\mathbf{7}$ & -1 & 40 & 1 & 5 & 1 & 2 & 0,439 & 0,32 \\
\hline $\mathbf{8}$ & 1 & 70 & 1 & 5 & 1 & 2 & 0,296 & 0,69 \\
\hline $\mathbf{9}$ & 0 & 55 & 0 & 4 & 0 & 1,25 & 0,341 & 0,59 \\
\hline $\mathbf{1 0}$ & 0 & 55 & 0 & 4 & 0 & 1,25 & 0,394 & 0,60 \\
\hline $\mathbf{1 1}$ & 0 & 55 & 0 & 4 & 0 & 1,25 & 0,382 & 0,46 \\
\hline
\end{tabular}

Obteve-se um modelo de regressão para os dados obtidos neste planejamento experimental, cujos coeficientes e demais parâmetros estatísticos são mostrados na Tabela 2. $\mathrm{O}$ coeficiente de determinação $r^{2}$ obtido foi de 0,8578 , o que indicaria que o ajuste deste modelo não possa ser considerado satisfatório. Porém, trata-se um resultado esperado, considerando possíveis variações no material utilizado neste trabalho (folhas de capimcidreira) e considerando possíveis erros experimentais, sobretudo na separação do óleo com a pipeta de Pasteur.

Tabela 2 - Coeficientes da regressão obtidos, desvios-padrão, e os valores tabelados para um intervalo de confiança de $95 \%$.

\begin{tabular}{|c|c|c|c|c|}
\hline Fator & Coeficiente & Desvio-padrão & $-95 \%$ interv. conf. & $+95 \%$ interv. conf. \\
\hline Média & 0,625455 & 0,051720 & 0,481857 & 0,769052 \\
\hline$T$ & $-0,057500$ & 0,121294 & $-0,394266$ & 0,279266 \\
\hline$t_{s}$ & $-0,237500$ & 0,121294 & $-0,574266$ & 0,099266 \\
\hline$t_{h}$ & $-0,252500$ & 0,121294 & $-0,589266$ & 0,084266 \\
\hline$T \times t_{s}$ & 0,367500 & 0,121294 & 0,030734 & 0,704266 \\
\hline$T \times t_{h}$ & 0,262500 & 0,121294 & $-0,074266$ & 0,599266 \\
\hline$t_{s} \times t_{h}$ & 0,192500 & 0,121294 & $-0,144266$ & 0,529266 \\
\hline
\end{tabular}

A Tabela 3 mostra os resultados obtidos a partir da análise de variância dos dados. Já a Figura 2 mostra o diagrama de Pareto e uma das superfícies de resposta. 


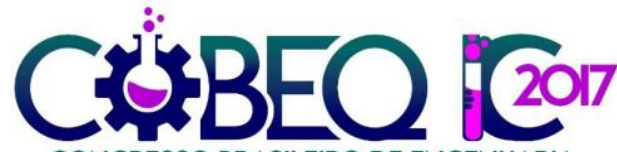 \\ CONGRESSO BRASILEIRO DE ENGENHARIA QUÍMICA EM INICIAÇÃO CIENTÍFICA \\ XII Congresso Brasileiro de Engenharia \\ Química em Iniciação Científica \\ UFSCar - São Carlos - SP \\ 16 a 19 de Julho de 2017}

Tabela 3 - Resultados da análise de variância sobre os dados experimentais, em que G.L. é o grau de liberdade, SQ é a soma de quadrados, QM é o quadrado médio, F é a Distribuição de

Fischer calculada e P é a probabilidade de significância.

\begin{tabular}{|c|c|c|c|c|c|}
\hline Fator & G. L. & SQ & QM & F & P \\
\hline$T$ & 1 & 0,006613 & 0,006613 & 0,224728 & 0,660178 \\
\hline$t_{s}$ & 1 & 0,112813 & 0,112813 & 3,833974 & 0,121826 \\
\hline$t_{h}$ & 1 & 0,127513 & 0,127513 & 4,333559 & 0,105817 \\
\hline$T \times t_{s}$ & 1 & 0,270113 & 0,270113 & 9,179871 & 0,038787 \\
\hline$T \times t_{h}$ & 1 & 0,137813 & 0,137813 & 4,683608 & 0,096438 \\
\hline$t_{s} \times t_{h}$ & 1 & 0,074113 & 0,074113 & 2,518740 & 0,187690 \\
\hline Erro puro & 2 & 0,117698 & 0,058849 & & \\
\hline Total & 10 & 0,846673 & & & \\
\hline
\end{tabular}

O único fator com significância estatística no intervalo testado foi o termo de interação do tempo de secagem com a temperatura. Este fato pode ser verificado na Tabela 2: o valor $p$ foi menor que 0,05 e o valor $F$ foi maior que o tabelado $(7,71)$ somente para esta combinação de variáveis. O diagrama de Pareto (Figura 2) também resume este fato. A influência da interação destes fatores pode ser explicada também pela volatilização do óleo durante a secagem (Figiel et al., 2010). Na Tabela 2 e na Figura 2, verifica-se também que o tempo de hidrodestilação não apresentou influência estatisticamente significativa no intervalo analisado. De fato, observou-se experimentalmente que, após cerca de $30 \mathrm{~min}$ de processo, houve o aumento do volume somente do hidrolato no intervalo de tempo analisado, sem aumento no volume do óleo essencial. Resultado análogo foi reportado por Martim et al. (2012) durante a obtenção de óleo essencial de capim-cidreira por hidrodestilação em Clevenger. Por outro lado, mesmo que tenha havido o cuidado para que a proporção massa de folhas por volume de água utilizado em cada experimento de hidrodestilação se mantivesse constante (conforme mostrado na Tabela 1), é possível ter havido influência desta variável no rendimento.

Figura 2 - Diagrama de Pareto.

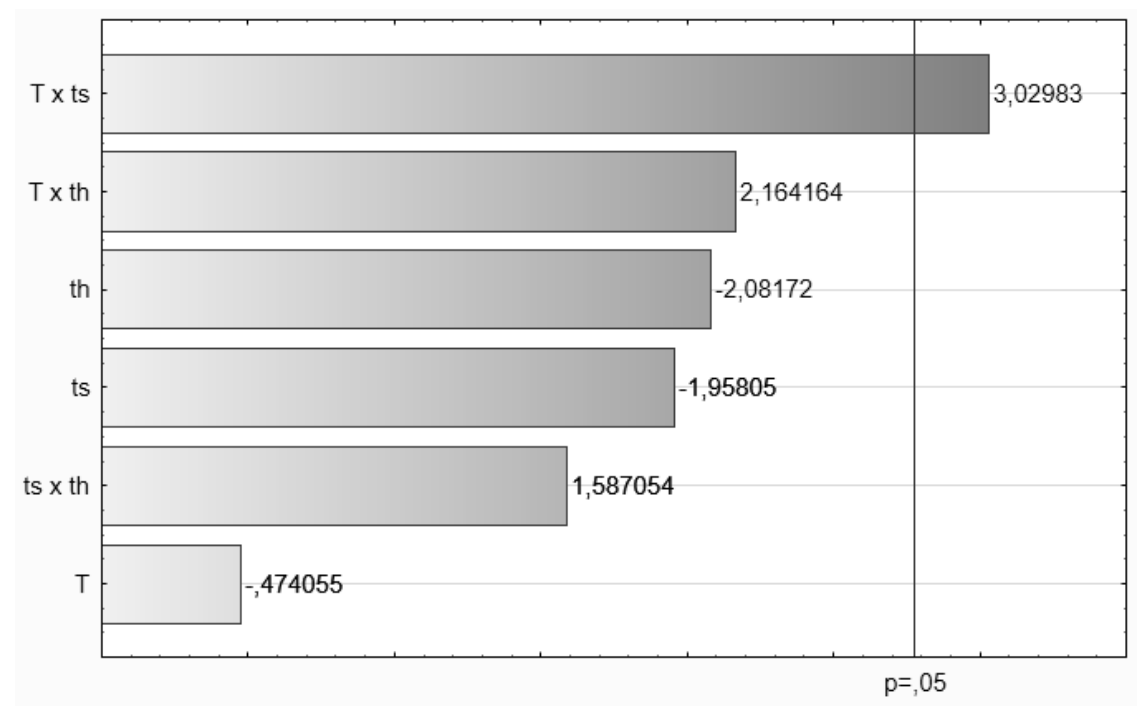




\section{CONCLUSÕES}

A partir dos dados mostrados neste trabalho, conclui-se que a secagem em estufa de convecção natural exerceu influência sobre o processo de obtenção de óleo essencial de folhas de capim-cidreira. Os parâmetros do processo de secagem que influenciaram sobre o rendimento em óleo essencial foram a temperatura e o tempo de secagem na estufa. Já o tempo de hidrodestilação não exerceu influência sobre o rendimento no intervalo analisado.

\section{REFERÊNCIAS BIBLIOGRÁFICAS}

ARABHOSSEINI, A.; PADHYE, S.; VAN BEEK, T. A.; VAN BOXTEL, A. J. B.; HUISMAN, W.; POSTHMUS, M. A.; MÜLLER, J. Loss of essential oil of tarragon (Artemisia dracunculus L.) due to drying. J. Sci. Food Agric., v. 86, p. 2543-2550, 2006.

BALTI, M. A.; KRIAA, K.; HADRICH, B.; KADRI, M. N.; KECHAOU, N. Effect of the drying on the yield and the composition of lemongrass essential oils. 19th IDS, p. 1-6, 2014.

BARboSA, L. C. A.; PEREIRA, U. A.; MARTinAZZO, A. P.; MALTHA, C. R. A.; TEIXEIRA, R. R.; MELO, E. C. Evaluation of chemical composition of commercial Cymbopogon citratus (D. C.) Stapf samples. Molecules, v. 13, p. 1864-1874, 2008.

BUCHAILLOT, A.; CAFFIN, N.; BHANDARI, B. Drying of lemon myrtle (Backhousia citriodora) leaves: retention of volatiles and color. Dry. Technol., v. 27 (3), p. 445450, 2009.

CARVALHO FILHO, J. L. S.; BLANK, A. F.; ALVES, P. B.; EHLERT, P. A. D.; MELO, A. S. CAVALCANTI, S. C. H.; ARRIGONI-BLANK, M. F.; SILVAMANN, R. Influence of harvesting time, temperature and drying period on basil (Ocimum basilicum L.) essential oil. Rev. Bras. Farmacogn., v. 16 (1), p. 24-30, 2006.

FIGIEL, A.; SZUMNY, A.; GUTIÉRREZ-ORTÍZ, A.; CARBONELL-BARRACHINA, A. A. Composition of oregano essential oil (Origanum vulgare) as affected by drying method. J. Food Eng., v. 98, p. 240-247, 2010.

GARCIA, V. S.; FERREIRA, M.C. Secagem de folhas de erva-cidreira em panela rotativa. Anais do XXXV ENEMP, p. 1-4, 2011.

KUBECZKA, K.-H. History and Sources of Essential Oil Research. In: BASER, K. H. C.; BUCHBAUER, G. (Eds.). Handbook of Essential Oils: Science, Technology and Applications. Boca Raton: CRC Press, p. 3-38, 2010.

MARTIM, E.; BIANCHI, A. A. R. T.; MARTIM, N. S. P. P.; CECCON, D. Extração de óleos essenciais a partir de capim-limão. Anais do XIX COBEQ, p. 7023-7027, 2012.

MEJRI, J.; ABDERRABBA, M.; MEJRI, M. Chemical composition of the essential oil of Ruta chapelensis L.: influence of drying, hydro-distillation duration and plant parts. Ind. Crop Prod., v. 32, p. 671-673, 2010.

NEGRELlE, R. R. B.; GOMES, E. C. Cymbopogon citratus (DC.) Stapf: chemical composition and biological activities. Rev. Bras. Pl. Med., v. 9, n. 1, p. 80-92, 2007. 